(c) 2018 IEEE. Personal use of this material is permitted. Permission from IEEE must be obtained for all other uses, in any current or future media, including reprinting/republishing this material for advertising or promotional purposes, creating new collective works, for resale or redistribution to servers or lists, or reuse of any copyrighted component of this work in other works. 


\section{Investigation of Grid-Connected and Islanded Direct Matrix Converter for Renewable Microgrid Applications with Model Predictive Control}

\author{
Jianwei Zhang, Li Li \\ Faculty of Engineering and IT \\ University of Technology Sydney \\ Sydney, Australia \\ Jianwei.Zhang@uts.edu.au \\ Li.Li@uts.edu.au
}

\author{
David G. Dorrell \\ Discipline of Electrical, Electronic and \\ Computer Engineering \\ University of KwaZulu-Natal \\ Durban, South Africa \\ dorrelld@ukzn.ac.za
}

\author{
Jose Rodriguez, Margarita Norambuena \\ Facultad de Ingeniería \\ Universidad Andrés Bello \\ Santiago, Chile \\ jose.rodriguez@unab.cl \\ margarita.norambuena@gmail.com
}

\begin{abstract}
The direct matrix converter has been proposed for many potential applications. However, it remains unexplored within the context of microgrids and distributed generation. This paper investigates the application of the direct matrix converter to these areas. Both the grid-connected and islanded operation modes are explored. Model predictive control is employed to achieve flexible active and reactive power regulation in the gridconnected mode, and stable sinusoidal voltage control in the islanded mode. It is also used to achieve grid voltage synchronization prior to grid connection. Simulation and experimental results verify the feasibility and effectiveness of the direct matrix converter when used in grid-connected and islanded microgrids. When used in the matrix converterconnected microgrid, model predictive control is effective in regulating the voltage and the power exchange with the grid.
\end{abstract}

Keywords-Matrix Converter; Model Predictive Control; Voltage Regulation; Microgrid; Distributed Generation

\section{INTRODUCTION}

AC-to-AC energy conversion systems are commonly used in industry and they can be found in the areas such as adjustable speed motor drives, power flow controllers and power quality conditioners [1]-[3]. In this regard, the indirect AC-to-AC; i.e., AC-DC-AC energy conversion systems have dominated most industrial applications. One of the shortcomings associated with the indirect AC-to-AC converter is the bulky DC-link capacitor. This capacitor leads to large physical converter dimensions, heavy weight, high maintenance, shortened lifetime and low reliability [4]. In addition, DC-link voltage control is usually necessary. In contrast, the direct matrix converter does not require any bulky energy-storage elements and can provide possible solutions to these problems [5][6].

A direct matrix converter is a direct AC-to-AC energy conversion system that is characterized by the compact volume, bidirectional power flow, controllable input power factor, regenerative capability [6][7]. A direct matrix converter is shown in Fig. 1. As seen, there is no bulky energy-storage element required in this structure. Due to the absence of the bulky DC-link capacitor, the lifetime, reliability and efficiency of the system can be improved, the operating temperature can be extended, and the maintenance can be reduced. Hence, the matrix converter is gaining interest from academics and industry. It has been considered for several possible application areas [8]-[11]. However, the application of the direct matrix converter in renewable microgrids and distributed generation has had little reporting in either the grid-connected or islanded mode.

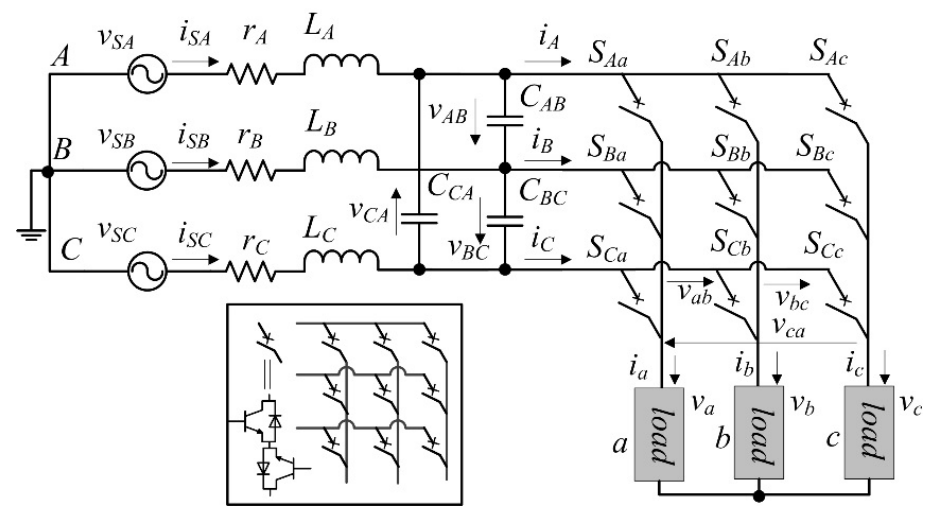

Fig. 1. A three-phase direct matrix converter system with input filters.

In recent decades, distributed generation and microgrids that include various renewable energy resources have become popular topics in the power industry since they can alleviate the environmental and energy issues. The development of the distributed generation and microgrids has demonstrated demand for AC/AC conversions [2]. A microgrid is often not suitable for direct connection to the utility grid because of the characteristics of the power produced by the renewable generation in the system. This leads to the development of the smart microgrid that is not directly synchronized to the grid and has its own power storage. This may also be DC. Therefore, a power electronic interface, e.g., DC/AC or $\mathrm{AC} / \mathrm{AC}$ converter, is usually required [13].

For $\mathrm{AC} / \mathrm{AC}$ conversion in microgrids, almost all research work and practical implementation use more the traditional indirect conversion, i.e., AC-DC-AC energy conversion [12]. Usually, this is achieved by using a rectifier and a voltage source inverter (VSI) [13][14]. The rectifier and VSI, or backto-back VSIs to allow bidirectional power flow, are connected 


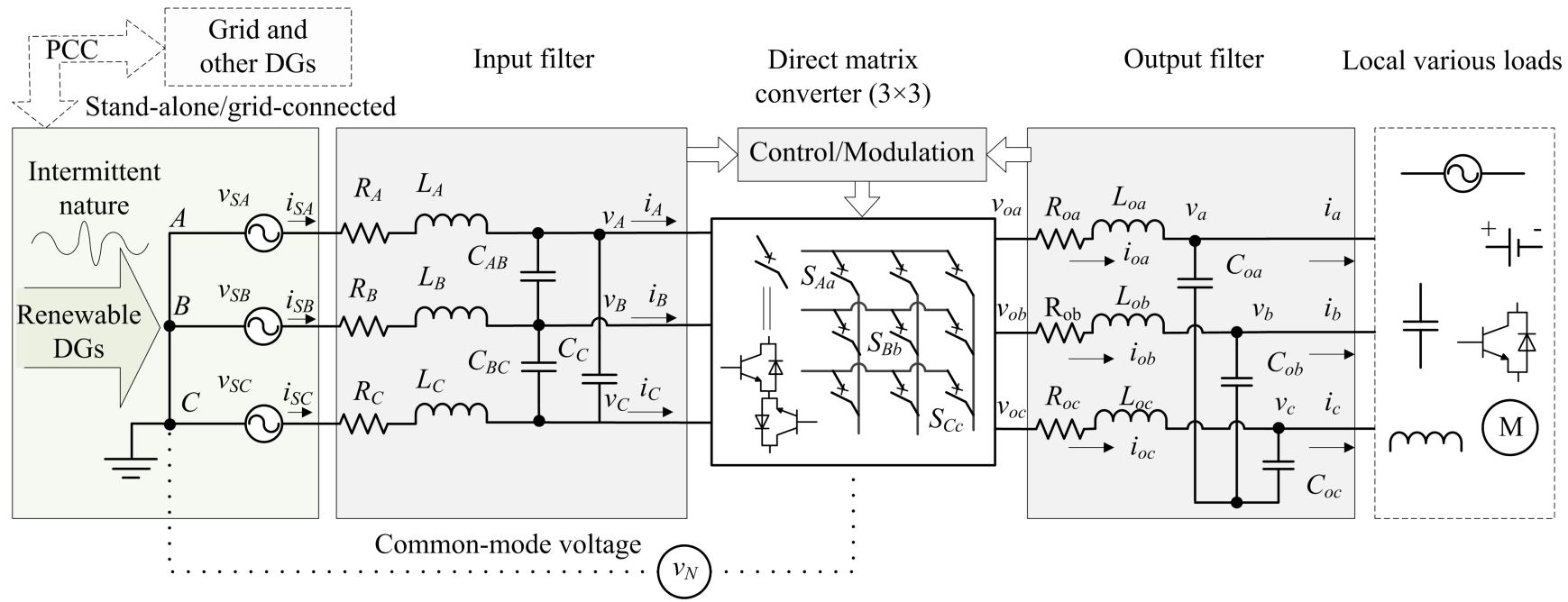

Fig. 2. AC microgrid with renewable distributed generators and matrix converter.

via a DC-link capacitor. In these structures, the problems associated with the bulky DC-link capacitor persist. In [2], the indirect matrix converter was used with distributed generations. The DC-link capacitor is not required because of the indirect matrix converter. The reverse operation mode of the indirect matrix converter is investigated to boost the output voltage. However, the AC-to-AC conversion is performed indirectly. In [5], a direct matrix converter was applied to regulate the output voltage in an islanded microgrid. However, the grid-connected mode was not investigated.

Motivated by these factors, a direct matrix converter is used in this work to interface the renewable distributed generation in a microgrid. A microgrid structure that involves a three-phase direct matrix converter is shown in Fig. 2. Both the grid-connected and islanded operation modes are investigated in this paper. $L C$ filters are employed to maintain the sinusoidal output voltage and establish the system model for the controller. The control strategy adopted in this paper is model predictive control (MPC) which is a simple and powerful controller for converters including matrix converters [15]-[17]. In the literature, most matrix converter control strategies regulate the sinusoidal output currents [18][19]. In this work, a stable output sinusoidal voltage in the islanded mode, and active and reactive power regulation in the gridconnected mode, are the main control objectives.

This paper is organized as follows. Section II presents the system modeling which is used to obtain the MPC prediction models. Section III explains the islanded and grid-connected operation. Simulation and experimental results are presented in Section IV, followed by the conclusions in Section V.

\section{SYSTEM MODELING}

\section{A. Matrix Converter Model}

As shown in Fig. 1, a three-phase direct matrix converter consists of nine bidirectional switches which form a $3 \times 3$ switch matrix. The output voltages and input currents can be controlled by controlling the switches. Their equations are shown in

$$
\begin{aligned}
{\left[\begin{array}{l}
v_{o a} \\
v_{o b} \\
v_{o c}
\end{array}\right]=} & {\left[\begin{array}{lll}
S_{A a} & S_{B a} & S_{C a} \\
S_{A b} & S_{B b} & S_{C b} \\
S_{A c} & S_{B c} & S_{C c}
\end{array}\right]\left[\begin{array}{l}
v_{A} \\
v_{B} \\
v_{C}
\end{array}\right]=S\left[\begin{array}{l}
v_{A} \\
v_{B} \\
v_{C}
\end{array}\right] } \\
{\left[\begin{array}{l}
i_{A} \\
i_{B} \\
i_{C}
\end{array}\right]=} & {\left[\begin{array}{lll}
S_{A a} & S_{A b} & S_{A c} \\
S_{B a} & S_{B b} & S_{B c} \\
S_{C a} & S_{C b} & S_{C c}
\end{array}\right]\left[\begin{array}{l}
i_{o a} \\
i_{o b} \\
i_{o c}
\end{array}\right]=S^{T}\left[\begin{array}{l}
i_{o a} \\
i_{o b} \\
i_{o c}
\end{array}\right] } \\
& \sum_{X=A, B, C} S_{X x}=1,(x=a, b, c)
\end{aligned}
$$

where $S$ and its transpose $S^{T}$ are switch matrices. The elements $S_{X x}$ in the switch matrix can have a value of one for the 'ON' state and zero for the 'OFF' state. Based on the measurements of $v_{A, B, C}$ and $i_{o a, o b, o c}, v_{o a, o b, o c}$ and $i_{A, B, C}$ can be calculated respectively, which will be utilized in the prediction models.

The constraint in (3) excludes the switch states that shortcircuit the inputs (usually voltage sources) or open-circuit the outputs (usually inductive loads). This is because these switch states can lead to detrimental overcurrents or overvoltages. As a result, there are 27 allowable switch states in the matrix and these states correspond to 27 control actions (finite control set) in the MPC.

\section{B. Output Filter Models}

The MPC implementation is based on the system model. According to Fig. 2, the output filters of the matrix converter are modeled as 


$$
\begin{aligned}
& \left\{\begin{array}{l}
v_{o a}-i_{o a} \cdot R_{o a}-L_{o a} \frac{d i_{o a}}{d t}=v_{a} \\
v_{o b}-i_{o b} \cdot R_{o b}-L_{o b} \frac{d i_{o b}}{d t}=v_{b} \\
v_{o c}-i_{o c} \cdot R_{o c}-L_{o c} \frac{d i_{o c}}{d t}=v_{c}
\end{array}\right. \\
& \left\{\begin{array}{l}
C_{o a} \frac{d v_{a}}{d t}=i_{o a}-i_{a} \\
C_{o b} \frac{d v_{b}}{d t}=i_{o b}-i_{b} \\
C_{o c} \frac{d v_{c}}{d t}=i_{o c}-i_{c}
\end{array}\right.
\end{aligned}
$$

The variables in (4) and (5) are shown in Fig. 2. The capacitors can be connected in star $\left(C_{A, B}, C\right)$ or delta $\left(C_{A B, B C}\right.$, $\left.{ }_{C A}\right)$. The feature of the star connection is that the required capacitance is three times $\left(C_{A}=3 C_{A B}\right)$ while the voltage rating is $1 / \sqrt{3}$ times $\left(V_{A B}=\sqrt{3} V_{A}\right)$ of that in the delta connection for the equivalent ratings. Due to the symmetry of the three-phase system, it is sufficient to consider a per-phase model:

$$
\begin{gathered}
v_{o a}-i_{o a} R_{o a}-L_{o a} \frac{d i_{o a}}{d t}=v_{a} \\
C_{o a} \frac{d v_{a}}{d t}=i_{o a}-i_{a}
\end{gathered}
$$

and this can be rewritten as a state space model:

$$
\begin{gathered}
{\left[\begin{array}{l}
\dot{i}_{o a} \\
\dot{v}_{a}
\end{array}\right]=F\left[\begin{array}{c}
i_{o a} \\
v_{a}
\end{array}\right]+G\left[\begin{array}{c}
v_{o a} \\
i_{a}
\end{array}\right] ;} \\
F=\left[\begin{array}{cc}
-R_{o a} / L_{o a} & -1 / L_{o a} \\
1 / C_{o a} & 0
\end{array}\right] ; G=\left[\begin{array}{cc}
1 / L_{o a} & 0 \\
0 & -1 / C_{o a}
\end{array}\right]
\end{gathered}
$$

where $F$ and $G$ are the state-space matrices. Using (8) and (9), the zero-order-hold $(\mathrm{ZOH})$ based discretized model can be derived from

$$
\begin{gathered}
{\left[\begin{array}{c}
i_{\text {oa }}[k+1] \\
v_{a}[k+1]
\end{array}\right]=A\left[\begin{array}{c}
i_{o a}[k] \\
v_{a}[k]
\end{array}\right]+B\left[\begin{array}{c}
v_{o a}[k] \\
i_{a}[k]
\end{array}\right] ;} \\
A=e^{F T_{s}} ; B=\int_{0}^{T_{s}} e^{F \tau} d \tau \cdot G
\end{gathered}
$$

where $T_{s}$ is the control sampling time and the matrices $A$ and $B$ are

$$
\begin{aligned}
& A=\left[\begin{array}{ll}
A_{11} & A_{12} \\
A_{21} & A_{22}
\end{array}\right] ; A_{11}=\frac{a e^{a T_{s}}-b e^{b T_{s}}}{a-b} ; A_{12}=\frac{-e^{a T_{s}}+e^{b T_{s}}}{L_{o a}(a-b)} \\
& A_{21}=\frac{e^{a T_{s}}-e^{b T_{s}}}{C_{a b}(a-b)} ; A_{22}=\frac{a e^{a T_{s}}-b e^{b T_{s}}}{a-b}+\frac{R_{o a}\left(e^{a T_{s}}-e^{b T_{s}}\right)}{L_{o a}(a-b)}
\end{aligned}
$$

$$
\begin{gathered}
B=\left[\begin{array}{ll}
B_{11} & B_{12} \\
B_{21} & B_{22}
\end{array}\right] ; B_{11}=\frac{e^{a T_{s}}-e^{b T_{s}}}{L_{o a}(a-b)} ; \\
B_{12}=\frac{a\left(e^{b T_{s}}-1\right)-b\left(e^{a T_{s}}-1\right)}{L_{o a} C_{o a} a b(a-b)} ; \\
B_{22}=\frac{-e^{a T_{s}}+e^{b T_{s}}+R_{o a}\left[a-b-a e^{b T_{s}}+b e^{a T_{s}}\right]}{L_{o a} C_{o a} a b(a-b)} \\
\text { with } a, b=\frac{-R_{o a} / L_{o a} \pm \sqrt{\left(R_{o a} / L_{o a}\right)^{2}-4 / C_{o a} / L_{o a}}}{2} .
\end{gathered}
$$

Therefore, the future behavior of the output voltage $v_{a}$ can be predicted from

$$
v_{a}[k+1]=A_{21} i_{\text {oa }}[k]+A_{22} v_{a}[k]+B_{21} v_{\text {oa }}[k]+B_{22} i_{a}[k]
$$

where $i_{o a}[k], v_{a}[k], i_{a}[k]$ are measured using sensors and $v_{o a}[k]$ is calculated using (1). It is worth mentioning that the observer can be adopted to estimate $i_{a}[k]$, which reduces the required sensors. More details can be found in [5]. Due to symmetry, the prediction models for other two phases can be derived readily. These voltage prediction models are used to regulate the output voltage in the islanded mode, and to achieve grid synchronization prior to the grid connection.

\section{Input Filter Models}

For the control at matrix converter input side, the input power factor is usually considered. In this regard, the models for the input filters can be developed in a similar manner to the output filter models. As a result, the prediction model of $i_{S A}$ can be obtained from

$$
i_{S A}[k+1]=M_{11} \cdot i_{S A}[k]+M_{12} \cdot v_{A}[k]+N_{11} \cdot v_{S A}[k]+N_{12} \cdot i_{A}[k](13)
$$

$M_{11}, M_{12}, N_{11}$ and $N_{12}$ can be derived using the ZOH-based discretization method in a similar manner to the output filter models. Here $i_{S A}[k], v_{A}[k]$ and $v_{S A}[k]$ can be obtained using sensors and $i_{A}[k]$ can be calculated using (2). $v_{S A}[k]$ can also be obtained by using an observer [5].

\section{Input Power Equations}

The input power factor can be controlled by controlling the input reactive power. The predicted reactive power can be calculated by the predicted current and voltage. For convenience, the $a b c$ system is converted into $\alpha \beta$ system using the following transformation

$$
\left[\begin{array}{l}
u_{\alpha} \\
u_{\beta}
\end{array}\right]=\left[\begin{array}{ccc}
\frac{2}{3} & -\frac{1}{3} & -\frac{1}{3} \\
0 & -\frac{1}{\sqrt{3}} & -\frac{1}{\sqrt{3}}
\end{array}\right]\left[\begin{array}{l}
u_{a} \\
u_{b} \\
u_{c}
\end{array}\right]
$$

where $u_{\alpha, \beta}$ and $u_{a, b, c}$ stand for the variables in the $\alpha \beta$ and $a b c$ systems. Thus, the predicted reactive power $Q_{S}[k+1]$ is calculated from 


$$
Q_{S}[k+1]=\frac{3}{2}\left(v_{S-\beta}[k+1] \cdot i_{S-\alpha}[k+1]-v_{S-\alpha}[k+1] \cdot i_{S-\beta}[k+1]\right)
$$

Here the supply voltage is assumed to be constant during a sampling period, i.e. $v_{S A, S B, S C}[k+1]=v_{S A, S B, S C}[k]$ thus $v_{S-\alpha}[k+1]$ $=v_{S-\alpha}[k]$ and $v_{S-\beta}[k+1]=v_{S-\beta}[k]$, because the sampling period is very short. A unity power factor is often desired, so the reactive power is controlled to zero by setting its reference to zero.

\section{E. Output Power Equations}

In the grid-connected mode, the microgrid is connected to a utility grid, and thus the main control objective is the flexible active and reactive power regulation. For the power equations, it is also sufficient to consider a per-phase model as shown in Fig. 3. The power equations can be obtained as from,

$$
\begin{gathered}
P_{g}=P+P_{c} \\
Q_{g}=Q+Q_{c} \\
P_{c}=0 \\
Q_{c}=\frac{\left|v_{g a-R M S}\right|^{2}}{2} \omega C_{o a}
\end{gathered}
$$

where $\omega$ is the output angular frequency and $\left|v_{g a-R M S}\right|$ is the root-mean-square (RMS) value of the grid voltage $v_{g a}$. Here $v_{g a}=v_{a}$ because of grid connection.

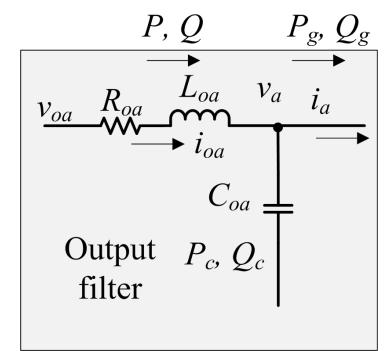

Fig. 3. Per-phase output filter structure.

In order to regulate the power using the MPC, the active and reactive power need to be predicted. To achieve this, the corresponding voltage and current should be predicted. However, the grid voltage is stable and barely changes within a short sampling period. Therefore, only the current needs to be predicted. In this regard, a prediction model of $i_{o a}$ can be derived from (10), as shown by

$$
i_{o a}[k+1]=A_{11} i_{o a}[k]+A_{12} v_{g a}[k]+B_{11} v_{o a}[k]+B_{12} i_{a}[k]
$$

In addition, (6) can also be utilized to derive a discretetime model to predict the future behavior of $i_{o a}$, as expressed by

$$
i_{o a}[k+1]=\frac{T_{s}}{L_{o a}}\left(v_{o a}[k]-v_{g a}[k]\right)+\left(1-\frac{T_{s}}{L_{o a}} R_{o a}\right) i_{o a}[k]
$$

Comparing (18) and (19), the latter method is less computationally intensive, and it does not require the information of $i_{a}[k]$, so it is adopted in this paper. In order to calculate the predicted power, the predicted current and the grid voltage in the $a b c$ frame are transformed into $\alpha \beta$ frame using (14). Then the corresponding active and reactive power can be computed using

$$
\begin{aligned}
& P[k+1]=\frac{3}{2}\left(v_{g-\alpha}[k+1] i_{o-\alpha}[k+1]+v_{g-\beta}[k+1] i_{o-\beta}[k+1]\right) \\
& Q[k+1]=\frac{3}{2}\left(v_{g-\beta}[k+1] i_{o-\alpha}[k+1]-v_{g-\alpha}[k+1] i_{o-\beta}[k+1]\right)
\end{aligned}
$$

where $v_{g-\alpha, \beta}$ and $i_{o-\alpha, \beta}$ represent the real and imaginary components of the corresponding variables $v_{g a, g b, g c}$ and $i_{o a, o b}$, $o c$. As mentioned earlier, it is assumed that $v_{g a, g b, g c}[k+1]=v_{g a}$, ${ }_{g b, g c}[k]$, thus $v_{g-\alpha}[k+1]=v_{g-\alpha}[k]$ and $v_{g-\beta}[k+1]=v_{g-\beta}[k]$ because the grid voltage is stable, and the sampling time is very short. The power predictions in (21) and (22) are used to regulate the active and reactive power flow in the grid-connected mode.

\section{MICROGRID OPERATION MODES}

\section{A. Islanded Operation}

In MPC, a cost function is designed to optimize the selection of switch states. Depending on the applications and control objectives, a cost function can contain several control variables. In the islanded mode, the microgrid is connected to local loads, so the main control task is to maintain a stable voltage supply to various local loads. In addition, the matrix converter input power factor is an important factor to consider. There are some other control objectives that can be included in the cost function, e.g., common mode voltage and switching frequency. Therefore, the cost function for the islanded mode is,

$$
\begin{aligned}
g_{1} & =\lambda_{1}\left\{\left|v_{a}^{*}-v_{a}[k+1]\right|+\left|v_{b}^{*}-v_{b}[k+1]\right|+\left|v_{c}^{*}-v_{c}[k+1]\right|\right\} \\
& +\lambda_{2}\left|Q_{S}^{*}-Q_{S}[k+1]\right|+\lambda_{3}\left|v_{N}^{*}-v_{N}[k+1]\right|+\lambda_{4} \sum_{i=1}^{9}\left|S_{i}-S_{i}[k+1]\right|
\end{aligned}
$$

where the variables denoted by the superscript ${ }^{*}$ are the references and their counterparts are the predicted values; $v_{N}[k+1]=\left(v_{a}[k+1]+v_{b}[k+1]+v_{c}[k+1]\right) / 3$ represents the predicted common-mode voltage and its desired reference $v_{N}{ }_{N}$ is normally zero; $S_{i}$ is the current switch state and $S_{i}[k+1]$ is the potential switch state to be applied; and $\lambda_{1,2,3,4}$ are the weighting factors which determine the priority for each term. Terms with greater factors attract more control attention. The main control objective here is to provide a stable output voltage supply. When several control objectives are considered at the same time, each control performance will be compromised. Designing these factors is usually based on empirical methods [35].

\section{B. Grid Synchronization}

For the grid synchronization, the main control goal is to regulate the output voltage to track the grid voltage, i.e. $\left[v^{*}{ }_{a}\right.$ $\left.v_{b}^{*} v_{c}^{*}{ }_{c}^{*}\right]=\left[\begin{array}{lll}v_{g a} & v_{g b} & v_{g c}\end{array}\right]$ should be assured. The cost function in (23) can be used and some terms can be removed depending on the control requirement. Once the grid synchronization is achieved, the microgrid can be connected to the utility grid. 


\section{Grid-Connected Operation}

Once the microgrid is connected to the utility grid, the main control goal changes to active and reactive power regulation. When there is excessive power generated in the microgrid or the utility grid needs support, the microgrid should be able to deliver the required energy to the utility grid with an appropriate control strategy. On the other hand, when the microgrid is insufficient to supply the local loads, it should be able to take power from the utility grid and supply to the local loads. That is, flexible power regulation and bidirectional power flow are essential. With MPC, this requirement can be fulfilled. The cost function for the grid-connected mode is

$$
g_{2}=\left|P^{*}-P[k+1]\right|+\left|Q^{*}-Q[k+1]\right|
$$

Here $P$ and $Q$ are controlled. The models and cost function can be revised accordingly to regulate $P_{g}$ and $Q_{g}$.

\section{SIMULATION AND EXPERIMENT RESULTS}

In order to verify the proposed application of a matrix converter in a microgrid, and the effectiveness of the proposed controller, simulation and experimental work are carried out. The system parameters are shown in Table I. The experimental setup is shown in Fig. 4. In this paper, the experimental tests are carried out for the islanded mode only. The experimental work for the grid-connected mode will be implemented in future work.

TABLE I. SYSTEM AND CONTROLLER PARAMETERS

\begin{tabular}{|c|c|c|c|c|c|c|c|c|}
\hline$v_{s}\left[\mathrm{~V}_{\mathrm{pk}-\mathrm{pk}}\right]$ & $L_{A}[\mathrm{n}$ & $\mathbf{a H}]$ & $C_{A L}$ & {$[\mu \mathrm{F}]$} & $\boldsymbol{R}_{A}[\Omega]$ & $L_{o a}$ & $\mathbf{m H}]$ & $C_{o a}[\mu \mathrm{F}]$ \\
\hline 100 & & 6.8 & & 9.5 & 0.5 & & 8 & 40 \\
\hline \multicolumn{9}{|c|}{ TABLE I. CONTINUED. } \\
\hline \multicolumn{2}{|c|}{$\boldsymbol{R}_{o a}[\mathbf{\Omega}]$} & $f_{s}[$ & Hz] & $f_{o}[\mathrm{~Hz}]$ & $Q^{*}[\mathrm{VA}$ & Ar] & $T_{s}[\mu \mathrm{s}]$ & \\
\hline & 0.5 & & 50 & 50 & & 0 & 80 & \\
\hline
\end{tabular}

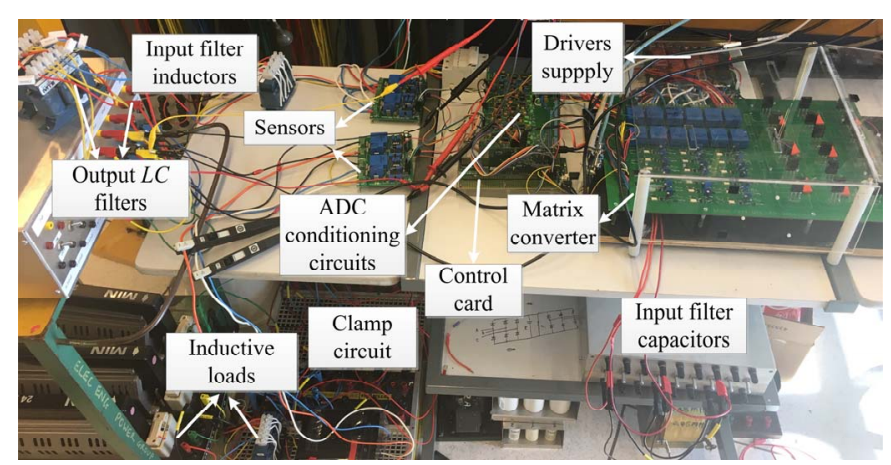

Fig. 4. Matrix converter prototype for the proposed scheme.

\section{A. Islanded Operation}

In the islanded operation, a stable voltage supply should be maintained for local loads under various conditions. Fig. 5 shows the steady-state output voltage waveforms for an inductive load $\left(R_{l}=20 \Omega, L_{l}=14 \mathrm{mH}\right)$ and the harmonic spectrum when operated in the islanded mode. The references are shown as black dashed lines. As can be seen, the output voltage can be regulated to supply a stable sinusoidal voltage to local loads. The total harmonic distortion (THD) is $2.97 \%$, which satisfies the requirement in most standards. The corresponding experimental work was carried out on the platform shown in Fig. 4. The experimental results are shown in Fig. 6. The output voltage is regulated to track the references effectively. These results show the effectiveness of the matrix converter when used in the islanded microgrid.

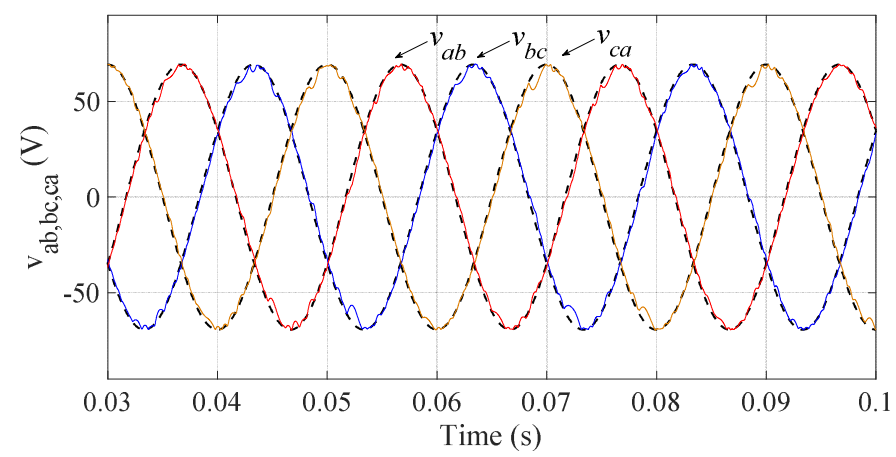

(a)

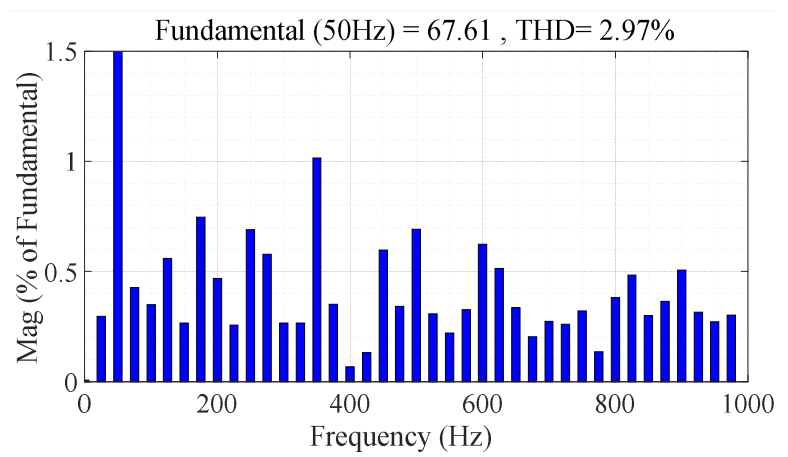

(b)

Fig. 5. Simulation results: (a) regulated output line-to-line voltages, (b) harmonic spectrum and THD for $v_{a b}$.

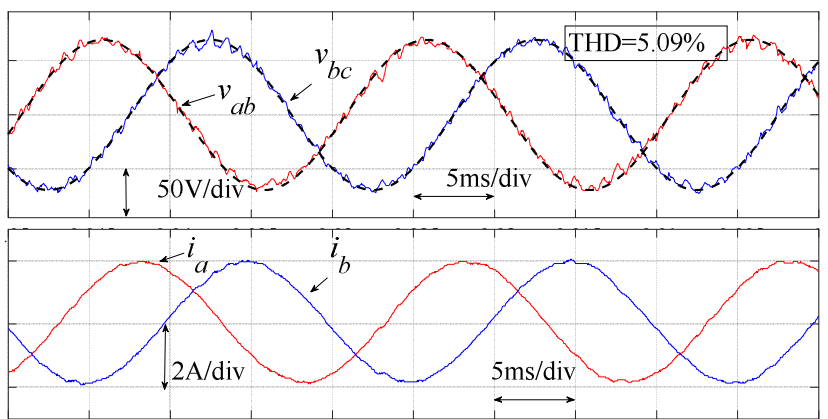

(a) 


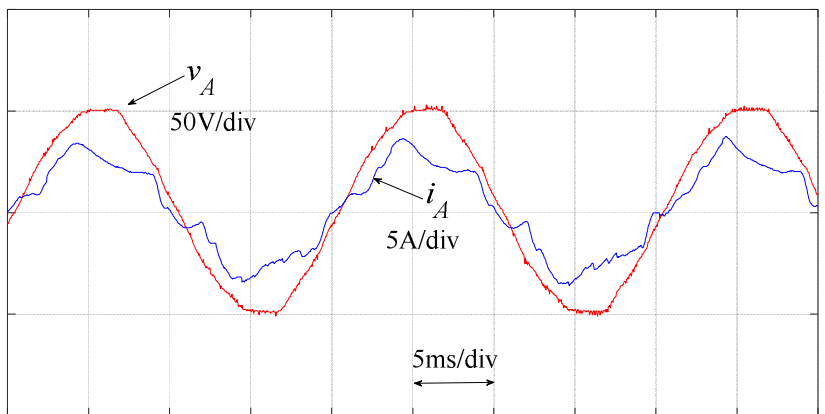

(b)

Fig. 6. Experimental waveforms: (a) output line-to-line voltage and phase currents, (b) source supply voltage and current.

An important feature of renewable distributed generation is the intermittence which should be considered in the controller design. In order to simulate the intermittence of a renewable distributed generation, a disturbance signal of $10 \times \sin (20 \pi t) \mathrm{V}$ is added to the supply as shown in Fig. 7. From Fig. 7, it can be observed that a stable output voltage can be maintained with the proposed scheme even when there is a significant disturbance in the supply.

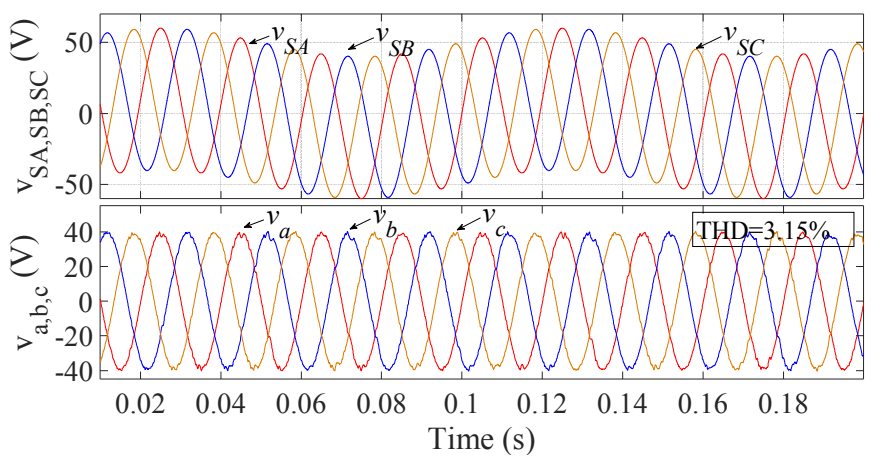

Fig. 7. Simulated intermittent source voltages and controlled output voltages.

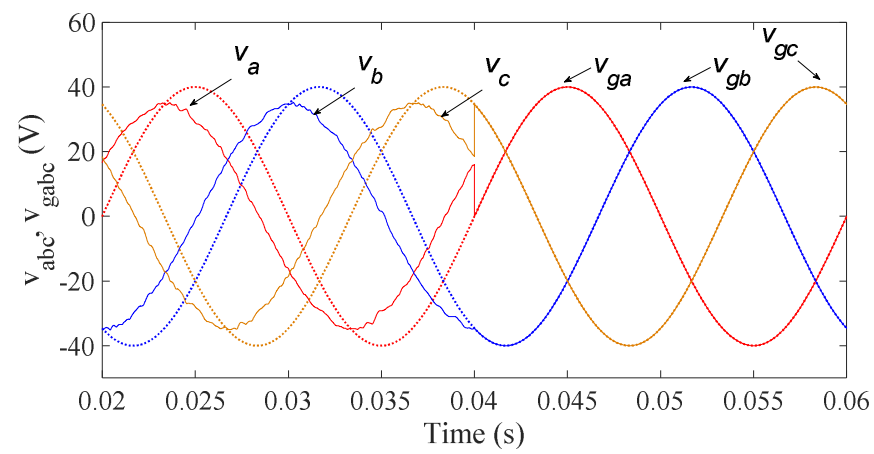

Fig. 8. Simulation waveforms of output and grid voltages during grid synchronization.

As indicated in the cost function (23) for the islanded mode, other variables such as input power factor, common mode voltage and switching frequency can be controlled when required. In addition, the proposed scheme can handle the unbalanced and nonlinear loads. The details and corresponding results can be found in [5].

\section{B. Grid Synchronization}

Before the microgrid is connected to the grid network, it is important to achieve grid synchronization. To this end, the grid voltages are measured and used as voltage references in the controller. Fig. 8 shows the regulated output voltage and grid voltage waveforms during grid synchronization. The grid voltages $\left[\begin{array}{lll}v_{g a} & v_{g b} & v_{g c}\end{array}\right]$ are shown by the dotted lines while the corresponding output voltages $\left[\begin{array}{lll}v_{a} & v_{b} & v_{c}\end{array}\right]$ are shown with the solid lines. The grid voltages are used as the references in the controller after $0.04 \mathrm{~s}$ to achieve grid synchronization for grid connection. As seen in Fig. 8, grid synchronization takes place with a fast-dynamic response. Once the voltage is synchronized, the output voltages closely match the grid voltages in terms of the frequency, phase and amplitude.

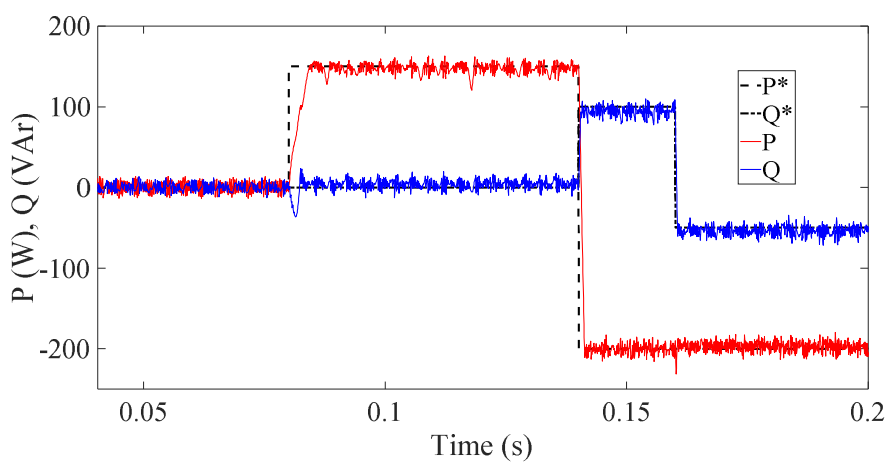

Fig. 9. Simulation results of regulated active and reactive power.

\section{Grid-Connected Operation}

The microgrid can be connected to the utility grid once grid synchronization is achieved. After grid connection, the main control objectives should switch to flexible active and reactive power regulation. Fig. 9 shows the regulated waveforms for active and reactive power flowing into the grid and local loads. The power references are represented by the black dashed lines. As observed in this figure, the regulated active and reactive power can track the prescribed references effectively. The microgrid can not only supply the power to local loads, but also provide power compensation for the utility grid when needed. The power can flow bidirectionally, as seen in Fig. 9.

\section{CONCLUSIONS}

The matrix converter has attracted interest and has been studied for several applications. However, its application in a microgrid with a distributed generation was underexplored and this paper seeks to address this issue. The application of a direct matrix converter in both grid-connected and islanded microgrids is investigated. The operating modes, including grid synchronization, are explained. In this work, MPC is employed as a control tool to regulate the sinusoidal output voltage in the islanded mode and power flow in the gridconnected mode. In the islanded mode, a stable voltage supply can be effectively maintained for various local loads. In the grid-connected mode, bidirectional and flexible power regulation is achieved. Before grid connection, it is important 
to achieve grid synchronization. The simulation and experimental results verify the effectiveness of the matrix converter when applied in a renewable microgrid. It is believed that the microgrid is a promising area for the matrix converter.

\section{REFERENCES}

[1] F. Blaabjerg, R. Teodorescu, M. Liserre, and A. V. Timbus, "Overview of control and grid synchronization for distributed power generation systems," IEEE Trans. on Ind. Electron., vol. 53, no. 5, pp. 1398-1409, 2006.

[2] X. Liu, P. Loh, P. Wang, F. Blaabjerg, Y. Tang, and E. A. Al-Ammar, "Distributed generation using indirect matrix converter in reverse power mode," IEEE Trans. on Power Electron., vol. 28, no. 3, pp. 1072-1082, 2013.

[3] J. Zhang, D. G. Dorrell, L. Li, Y. Guo, "Decoupling controller design and controllable regions analysis for the space vector modulated matrix converter-unified power flow controller in transmission systems," Electric Power Components Systems, vol. 46, no.1, pp. 1-14, 2018.

[4] J. Kolar, T. Friedli, J. Rodriguez, and P. W. Wheeler, "Review of threephase PWM AC-AC converter topologies," IEEE Trans. on Ind. Electron., vol. 58, no. 11, pp. 4988-5006, 2011.

[5] J. Zhang, L. Li, Z. Malekjamshidi, and D. G. Dorrell, "Predictive Voltage Control of Direct Matrix Converter with Reduced Number of Sensors for the Renewable Energy and Microgrid Applications," IEEE Energy Conversion Congress and Exposition (ECCE), Cincinnati, USA, pp. 3309-3315, Oct. 2017.

[6] P. Wheeler, J. Rodriguez, J. C. Clare, L. Empringham, and A. Weinstein, "Matrix converters: A technology review," IEEE Trans. on Ind. Electron., vol. 49, no. 2, pp. 276-288, 2002.

[7] J. Rodriguez, M. Rivera, J. W. Kolar, and P. W. Wheeler, "A review of control and modulation methods for matrix converters," IEEE Trans. Ind. Electron., vol. 59, no. 1, pp. 58-70, 2012.

[8] J. Zhang, L. Li, and D. Dorrell, "Investigation of Direct Matrix Converter Working as a Versatile Converter (AC/AC, AC/DC, DC/AC, DC/DC Conversion) with Predictive Control," In 43rd Annual Conference Industrial Electronics Society, IEEE IECON 2017, Beijing, China, 2017.
[9] P. Zanchetta, P. W. Wheeler, J. C. Clare, M. Bland, L. Empringham, and D. Katsis, "Control design of a three-phase matrix-converter-based ac-ac mobile utility power supply." IEEE Trans. on Ind. Electron., vol. 55, no. 1, pp. 209-217, 2008.

[10] J. Zhang, D. G. Dorrell and L. Li, "Applications of the Direct Space Vector Modulation Controlled Matrix Converter as the Unified Power Flow Controller," The 8th Int. Conf. on Power Electron., Machines \& Drives (PEMD 2016), Glasgow, pp. 1-6, 2016.

[11] J. Zhang, H. Yang, T. Wang, L. Li, and D. G. Dorrell, "Field- oriented control based on hysteresis band current controller for a permanent magnet synchronous motor driven by a direct matrix converter," IET Power Electronics, vol. 11, no. 7, pp. 1277-1285, 2018.

[12] J. Rocabert, A. Luna, F. Blaabjerg, and P. Rodriguez, "Control of power converters in AC microgrids," IEEE Trans. Power Electron., vol. 27, no. 11, pp. 4734-4749, 2012.

[13] J. P. Lopes, C. L. Moreira, and A. G. Madureira, "Defining control strategies for microgrids islanded operation," IEEE Trans. power systems, vol. 21, no. 2, pp. 916-924, 2006.

[14] J. C. Vasquez, J. M. Guerrero, A. Luna, P. Rodríguez, and R. Teodorescu, "Adaptive droop control applied to voltage-source inverters operating in grid-connected and islanded modes," IEEE Trans. Ind. Electron., vol. 56, no. 10, pp. 4088-4096, 2009.

[15] S. Kouro, P. Cortés, R. Vargas, U. Ammann and J. Rodríguez, "Model predictive control-A simple and powerful method to control power converters," IEEE Trans. Ind. Electron., vol. 56, no. 6, pp. 1826-1838, 2009.

[16] S. Vazquez, J. I. Leon, L. G. Franquelo, J. Rodriguez, H. A. Young, A. Marquez, and P. Zanchetta, "Model predictive control: A review of its applications in power electronics," IEEE Ind. Electron. Magazine, vol. 8, no. 1, pp. 16-31, 2014.

[17] J. Rodriguez, M. P. Kazmierkowski, J. R. Espinoza, P. Zanchetta, H. Abu-Rub, H. A. Young and C. A. Rojas, "State of the art of finite control set model predictive control in power electronics," IEEE Trans. Ind. Informatics, vol. 9, no. 2 pp. 1003-1016, 2013.

[18] M. Rivera, C. Rojas, J. Rodríguez, P. Wheeler, B. Wu, and J. R. Espinoza, "Predictive current control with input filter resonance mitigation for a direct matrix converter," IEEE Trans. Power Electron., vol. 26, no. 10, pp. 2794-2803, 2011.

[19] M. Rivera, A. Wilson, C. A. Rojas, J. Rodriguez, J. R. Espinoza, P. W. Wheeler, and L. Empringham, "A comparative assessment of model predictive current control and space vector modulation in a direct matrix converter," IEEE Trans. Ind. Electron., vol. 60, no. 2, pp. 578-588, 2013. 